\title{
A PHOTOELECTRON SPECTROSCOPIC INVESTIGATION OF CONDUCTING POLYPYRROLE-POLYAMIDE COMPOSITE FILM
}

Sefik Suzer, Bilkent University, Dept. of Chemistry, 06533 Ankara, Turkey, Levent Toppare, Middle East Technical University, Dept. of Chemistry, 06531, Ankara, Turkey

and

Geoffrey C. Allen and Keith R. Hallam, University of Bristol, Interface Analysis Center, Bristol BS2 8BS, England

\begin{abstract}
X-ray photoelectron spectrum of the electrochemically prepared polypyrrole and polypyrrole-polyamide composite films exhibit an additional strong high binding energy peak at $402.0 \mathrm{eV}$ corresponding to $\mathrm{N}^{+}$moieties. Intensity of this peak is significantly reduced upon electrochemical reduction. Atomic concentrations derived from the observed $\mathrm{N}^{+}$and $\mathrm{F}$ (stemming from the dopant $\mathrm{BF}_{4}^{-}$) peaks reveal a slightly higher cation/anion ratio for this composite and suggest that the composite has a different chemical composition than the corresponding polymers.
\end{abstract}

\section{Introduction}

Of the many conducting polymers polypyrrole is the most studied one ${ }^{1}$. Use of electron spectroscopic methods for various structural determinations of conducting polymers has been reviewed recently 2,3 . Chemically or electrochemically prepared polypyrrole has poor mechanical properties ${ }^{1}$, and various physical and/or chemical methods have been utilized to improve these properties. Blending or making composites with other polymers having better mechanical properties have been successful for many applications 4,5 . Polyamide (PA) has proved to be especially successful. In our previous studies we have shown that electrochemically prepared blends of polypyrrole-polyamide composite films have better mechanical and/or electrical properties 6 . In this contribution we report an $x$-ray photoelectron spectroscopic investigation of these films. 


\section{Experimental}

PPy/PA composites were prepared by electrochemical polymerization of pyrrole onto a polyamide coated electrode at a constant predetermined potential. The polyamide films were dipcoated from chloroform solution of a concentrated polyamide resin (Aldrich Co. 19, 101-9). The potentiostatic polymerization was carried out in a three compartment cell equipped with $\mathrm{Pt}$ foils $\left(1.0 \mathrm{~cm}^{2}\right.$ each) as working (at $\left.+1.1 \mathrm{~V}\right)$ and counter electrodes and a capillary reference electrode $\left(\mathrm{Ag}_{\mathrm{Ag}}{ }^{+}\right)$. The solvent-electrolyte couple was acetonitrile -tetrabutylammonium tetrafluoroborate. Films having only the polypyrrole and only polyamide have also been prepared using the same procedure for comparison. Electrochemical reduction was achieved by reversing the polarity and discharging the prepared composite in the cell. X-ray photoelectron spectra of the various films are recorded after washing and drying the films while intact on their platinum electrodes. The spectrometer used is a Kratos ES300 using AlKa source.

\section{Results and Discussion}

Figure 1 depicts the spectrum of the polyamide (PA), polypyrrole (PPy), and polyamide-polypyrrole composite film as prepared (PA/PPy) and after electrochemical reduction (PA/PPy reduced). The main features are due to $F$ 1s peak of the dopant anion (tetrafluoroborate ion), $O 1 \mathrm{~s}, \mathrm{~N} 1 \mathrm{~s}$ and $\mathrm{C} 1 \mathrm{~s}$. On the side of the figure detailed $N$ 1s regions of the spectra are also included. Except for the polyamide this region displays more than one component which are deconvoluted into two main peaks. The peak at $399.7 \mathrm{eV}$ is assigned to the neutral polypyrrole and/or polyamide nitrogen and the higher binding energy peak at ca. $402.0 \mathrm{eV}$ is assigned to nitrogen carrying positive charge, in agreement with reported data $1,3,7-9$. Besides the binding energies, atomic concentrations have also been computed using peak intensities corrected for the corresponding sensitivity factors and are given in Table I.

The high binding energy component assigned to $\mathrm{N}^{+}$moieties have been reported to correlate with electronic conductivity of the polypyrrole ${ }^{9}$, hence it is logical to expect a linear correlation of the intensity of this peak with the corresponding dopant peaks i.e. F 1s. The last column of the table gives the 
$\mathrm{N}^{+}$to $\mathrm{F}$ atomic ratios divided by 4 to account for the stoichiometry (there are 4 $\mathrm{F}$ atoms for every anion, $\mathrm{BF}_{4}^{-}$). This ratio is 0.9 for polypyrrole and 1.1 for the composite, however it increases to 1.8 after electrochemical reduction of the composite. The oxygen concentration of the composite is also considerably less which may be an indication of the enhanced stability of the film in air. It is clear, however, that the composite is chemically different from its components as was postulated in our earlier study ${ }^{6}$ where the difference was confirmed using pyrolysis FTIR and mass spectrometric results.

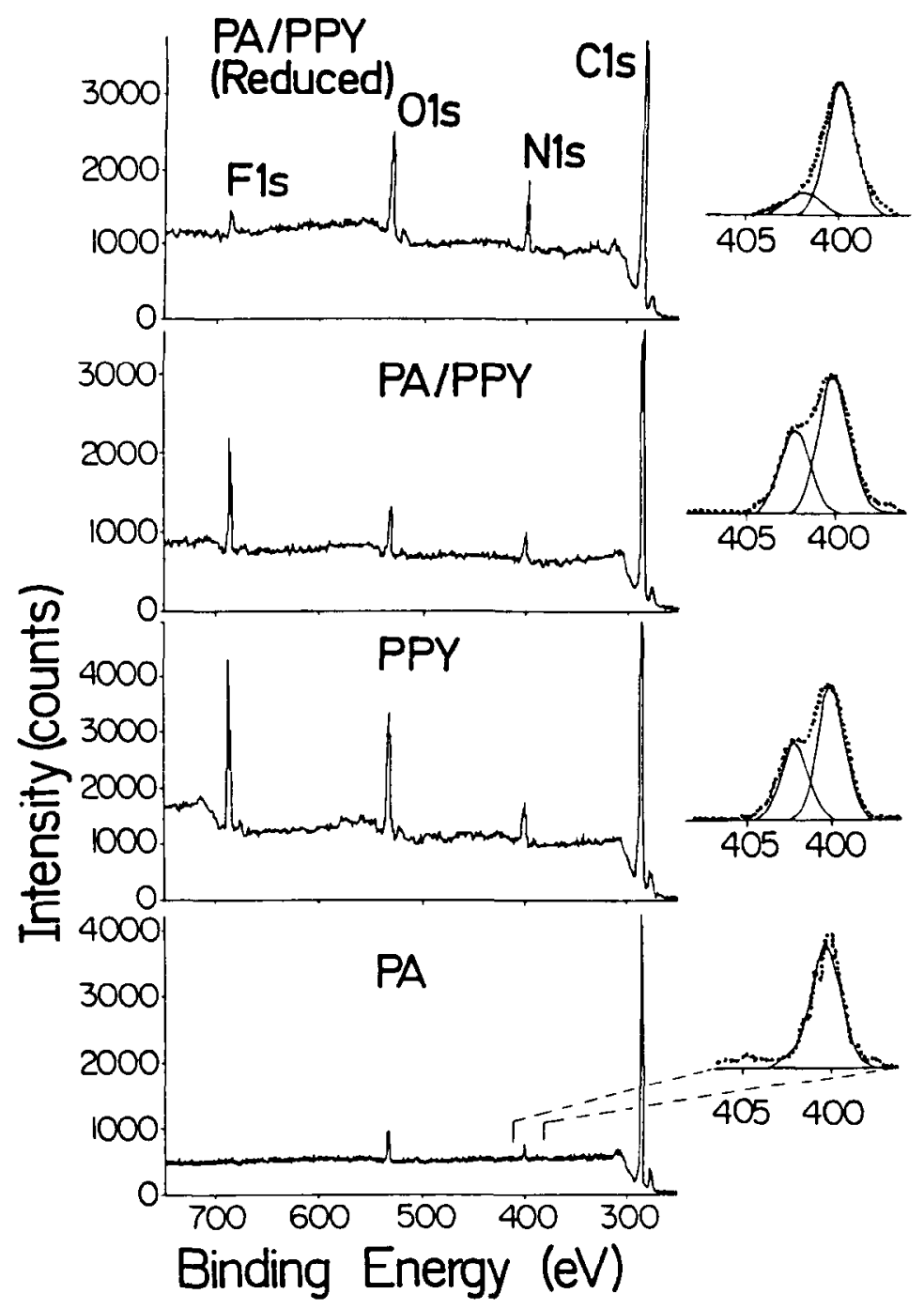

Figure 1. Al Ka x-ray photoelectron spectra of polyamide-only (PA), polypyrrole-only (PPY), polypyrrole-polyamide (PA/PPY) composite film as prepared (PA/PPY), and after electrochemical reduction (PA/PPY Reduced). The N is region for each polymer is given on the side. For polypyrrole and the composite, $\mathrm{N}$ 1s region displays more than one component which is deconvoluted into two gaussian peaks. The first one at $399.7 \mathrm{eV}$ is assigned to nitrogen in neutral polypyrrole and the second one at ca. $402.0 \mathrm{eV}$ is assigned to nitrogen carrying positive charge. 
Acknowledgments: This work is partially supported by TUBITAK, through the project TBAG-U/15-7. The authors are thankful to Fatma Selampinar for the help in preparation of the samples.

\section{References}

1- G.B. Street, Handbook of Con. Poly. I, Chapter 8(1984) 1281.

2- W.R. Salaneck, Rep. Prog. Phys. 54(1991) 1215.

3- E.T. Kang, K.G. Neoh and K.L. Tan, Adv. Polym. Sci. 106(1993) 135.

4- M. De Paoli, R.J. Waltmann, A.F. Diaz and J. Bargon, J. Chem. Soc., Chem. Commun. 1015(1984).

5- H.L. Wang, L. Toppare, J.E. Fernandez, Macromolecules 23(1990) 1053.

6- F. Selampınar, U. Akbulut, T. Yalcin, S. Suzer and L. Toppare, Synth. Met. 62 (1994) 201.

7- P. Pfluger and G.B. Street, J. Chem. Phys. 80(1984) 544.

8- J.G. Eaves, H.S. Munro and D. Parker, Polymer Commun. 28 (1987) 38.

9- G.G. McLeod, K. Jefreys, J.M.R. MacAllister, J. Mundell, S. Affrossman and R.A. Pethrick, J. Phys. Chem. Solids. 48(1987) 921.

Table I. Binding Energies (in eV) and \% Atomic Concentrations (given in parenthesis) ${ }^{a}$

\begin{tabular}{|c|c|c|c|c|c|c}
\hline \multirow{2}{*}{ C1s } & \multicolumn{2}{|c|}{$\mathrm{N} 1 \mathrm{~s}$} & O1s & F1s & $\mathrm{N}^{+} / 0.25^{\star} \mathrm{F}^{\mathrm{t}}$ \\
\cline { 3 - 6 } & & $(-\mathrm{N}-)$ & $\left(-\mathrm{N}^{+}-\right)$ & & & \\
\hline PA & 285.0 & 399.8 & - & 532.4 & - & - \\
& $(92.4)$ & $(1.6)$ & - & $(6.0)$ & & \\
\hline PPy & 285.0 & 399.7 & 402.0 & 532.3 & 686.3 & \\
& $(64.7)$ & $(5.4)$ & $(3.0)$ & $(13.6)$ & $(13.2)$ & 0.9 \\
\hline PA/PPy & 285.0 & 399.7 & 401.8 & 532.3 & 686.3 & \\
& $(74.1)$ & $(5.0)$ & $(3.1)$ & $(6.6)$ & $(11.2)$ & 1.1 \\
\hline PPy/PA & 285.0 & 399.7 & 401.8 & 532.3 & 686.3 & \\
(Reduced) & $(70.7)$ & $(9.7)$ & $(1.5)$ & $(14.7)$ & $(3.4)$ & 1.8 \\
\hline
\end{tabular}

aAtomic concentrations are computed from the observed intensities corrected for their corresponding sensitivity factors. bSince the anion $\mathrm{BF}_{4}^{-}$has 4 fluorine. 